\title{
MANAJEMEN PERSEDIAAN OBAT APOTEK LESTARI KOTA DUMAI
}

\author{
Wiwik Waroka ${ }^{(1)}$, Melliana ${ }^{(2)}$, \\ Elisa Hafrida ${ }^{(3)}$ \\ ${ }^{1,2,3)}$ Program Studi Teknik Industri, \\ Sekolah Tinggi Teknologi Dumai \\ Jl. Utama Karya Bukit Batrem II \\ Email: wiwikwarokah@gmail.com; \\ mellianna52@gmail.com; \\ hafridae@gmail.com
}

\begin{abstract}
ABSTRAK
Apotek Lestari berada jalan Jendral Sudirman No 215 Kota Dumai menjadi salah satu apotek yang banyak dituju oleh masyarakat sekitar. Berdasarkan pernyataan dari pengelola Aporek Lestari, selama ini pengendalian persediaan obat yang dilakukan hanya dengan memantau stok obat. Pemesanan hanya dilakukan jika stok obat menipis. Tidak ada pengelompokkan obat dan perhitungan khusus untuk menentukan jumlah pemesanan kembali, jumlah pemesanan hanya berdasar perkiraan saja. Metode yang digunakan dalam penelitian ini adalah metode Always Better Control (ABC) yang dapat membantu pihak manajemen menentukan pengendalian yang tepat untuk masing-masing kelompok obat dan menentukan obat yang harus diprioritaskan untuk meningkatkan efisiensi dan mengurangi biaya. Obat yang diprioritaskan diramalkan dengan metode Forecasting untuk menentukan persediaan kedepannya. Selanjutnya obat yang harus diprioritaskan akan dihitung menggunakan metode Economic Order Quantity (EOQ) untuk mengetahui jumlah optimum pemesanan yang dapat mengefesiensikan biaya yang akan dikeluarkan. Hasil penelitian ini jumlah pemesanan yang ekonomis (EOQ) untuk obat Paracetamol adalah 152 tablet dengan total cost Rp 292.601, untuk obat Folamil Genio adalah 183 botol dengan total cost $\mathrm{Rp} 292.579$, untuk obat Lansoprazole adalah 130 tablet dengan total cost $\mathrm{Rp}$ 292.616, untuk obat Amlodipine adalah 127 tablet dengan total cost Rp 292.619 dan untuk obat Domperidone adalah 95 tablet dengan total cost $\mathrm{Rp} 292.615$.

Kata kunci: Biaya Pesan, Biaya Simpan, EOQ
\end{abstract}

\section{ABSTRACT}

Apotek Lestari is located at Jalan Jendral Sudirman No. 215, Dumai City, which is one of the pharmacies that is widely targeted by the surrounding community. Based on a statement from the manager of Aporek Lestari, so far the control of drug supplies has been carried out only by monitoring drug stocks.. The method used in this study is the Always Better Control $(A B C)$ method which can help management determine the appropriate control for each drug group and determine which drugs should be prioritized to increase efficiency and reduce costs. The prioritized drugs are forecasted using the Forecasting method to determine future inventories. Furthermore, the drugs that must be prioritized will be calculated using the Economic Order Quantity (EOQ) method to find out the optimum number of orders that can streamline the costs to be incurred. The results of this study are the number of economical orders (EOQ) for Paracetamol drugs is 152 tablets with a total cost of Rp 292,601, for Folamil Genio drugs are 183 bottles with a total cost of $R p$ 292,579, for Lansoprazole drugs are 130 tablets with a total cost of $R p$ 292,616, for Amlodipine drugs is 127 tablets with a total cost of Rp 292,619 and for Domperidone is 95 tablets with a total cost of $R p$ 292,615.

Keywords: Order Cost, Saving Cost, EOQ 


\section{Pendahuluan}

Apotek Lestari berada jalan Jendral Sudirman No 215 Kota Dumai menjadi salah satu apotek yang banyak dituju oleh masyarakat sekitar. Berdasarkan pernyataan dari pengelola Aporek Lestari, selama ini pengendalian persediaan obat yang dilakukan Apotek Lestari hanya dengan memantau stok tiap-tiap obat. Pemesanan hanya dilakukan jika stok obat menipis. Tidak ada pengelompokkan obat dan tidak ada perhitungan khusus untuk menentukan jumlah pemesanan kembali, jumlah pemesanan hanya berdasar perkiraan saja. Hal ini mengakibatkan jumlah pemesanan tidak jelas, tidak jarang terjadi jumlah stok obat tidak sesuai dengan jumlah fisik obat yang ada di penyimpanan. Kejadian seperti ini akan menyebabkan tidak terkontrolnya persediaan obat. Kekurangan ataupun kelebihan persediaan merupakan gejala yang kurang baik pada Apotek. Kekurangan dapat berakibat larinya konsumen sedangkan kelebihan persediaan dapat mengakibatkan pemborosan atau tidak efisien. Untuk itu diperlukan suatu sistem perencanaan persediaan yang baik dan tepat guna menunjang operasi usaha tersebut agar dapat berjalan dengan lancar.

Darmawa, dkk (2021) melakukan penelitian dengan judul Analisis Pengendalian Persediaan Obat BPJS Kategori A (Always) dan E (Esensial) dengan Menggunakan Metode ABC, VEN Dan EOQ di IFRS Bhayangkara Tingkat III Nganjuk. Tujuan dilakukannya penelitian yaitu untuk melakukan analisa terhadap kendali obat BPJS kategori $\mathrm{AE}$ menggunakan $\mathrm{ABC}$ and $\mathrm{VEN}$ method, menganalisa pengendalian ketersediaan obat obat BPJS dengan metode EOQ dan ROP dalam peningkatan obat menjadi efisien serta menganalisa tingkat pelayanan obat. Dari uji analisis menggunakan metode $\mathrm{ABC}$ dan VEN dapat mengidentifikasi obat yang memerlukan pengendalian persediaan yang lebih ketat dan dengan penerapan metode EOQ dan ROP sebelum intervensi dan setelah intervensi dapat meningkatkan efesiensi pengelolaan obat BPJS dan menurunkan nilai persediaan. Dyatmika dan Krisnadewara (2017) juga melakukan penelitian Pengendalian Persediaan Obat Generik dengan Metode Analisis ABC, Metode Economic Order Quantity (EOQ), dan Reorder Point (ROP) Di Apotek XYZ Tahun 2017. Hasil analisis menunjukkan adanya perhitungan EOQ dan ROP bermanfaat untuk membantu Apotek dalam pengadaan obat generik sehingga terjadi keseimbangan antara tingkat pelayanan dan biaya.

Metode analisa ABC adalah metode pembuatan grup atau penggolongan berdasarkan peringkat nilai dari nilai tertinggi hingga terendah, dan dibagi menjadi tiga kelompok besar yang sebut kelompok A, kelompok B dan kelompok C. Analisis ABC bertujuan untuk membagi seluruh persediaan dalam perusahaan menjadi tiga kelompok, yaitu kelompok A,B,C. Kemudian, berdasarkan kelompok tersebut dapat ditentukan level persediaan yang harus dikendalikan secara umum. Berikut klasifikasinya ABC menurut Darmawan, dkk (2021):

a. Kelompok A

Merupakan kelompok barang yang kritis terhadap fungsi dan operasi sebuah perusahaan. Tingkat persediaan kelompok ini harus di monitor secara hati-hati. Kelompok barang ini memiliki volume keuangan yang tinggi dimana jumlah barang hanya sebesar 10\% dari seluruh persediaan, namun mencakup lebih dari $70 \%$ keuangan. b. Kelompok B

Merupakan kelompok barang yang penting, namun tidak kritis. Sehingga, tidak diperlukan pengendalian secara konstan untuk seluruh jenis barang ini. Kelompok ini mewakili sekitar 20\% keuangan dan jumlahnya sekitar 20\% dari seluruh persediaan. 


\section{c. Kelompok C}

Merupakan kelompok barang yang tidak terlalu penting terhadap suatu perusahaan. Kelompok barang ini mungkin hanya mewakili $10 \%$ dari keuangan perusahaan, namun jumlah itemnya sebesar $70 \%$ dari seluruh persediaan.

Economic Order Quantity (E0Q) adalah teknik kontrol persediaan yang meminimalkan biaya total dari pemesanan dan penyimpanan. Terdapat juga persamaan yang dikenal dalam system EOQ. Persamaan dalam Model EOQ tersebut sebagai berikut (Heizer \& Render, 2015):

$\mathrm{EOQ}=\sqrt{\frac{2 \cdot \mathrm{D} \cdot \mathrm{A}}{\mathrm{I}}}$

Dimana:

$\mathrm{D}:$ permintaan (demand)

Q : kuantitas optimal (quantity optimal)

A : biaya pemesanan (cost of ordering)

I : biaya penyimpanan (cost of holding)

Reorder point (ROP) adalah tingkat (titik) persediaan. dimana Tindakan harus diambil untuk mengisi kembali persediaan barang (Heizer \& Render, 2015). Rumus ROP adalah sebagai berikut (Heizer \& Render, 2015):

$\mathrm{ROP}=\mathrm{d} \times \mathrm{L}$

Dimana:

$\mathrm{d}$ : jumlah permintaan per hari

$\mathrm{L}$ : lead time atau waktu tunggu, yaitu waktu antara penempatan pesanan dan menerimanya

\section{Metode Penelitian}

Penelitian ini dilakukan di Apotek Lestari Kota Dumai yang beralamat di Jalan Jendral Sudirmal, Dumai. Waktu Penelitian dari bulan Agustus 2021 hingga November 2021. Populasi dalam penelitian ini adalah semua jenis obat yang terjual pada Apotek Lestari pada bulan Januari 2020 hingga September 2021, sehingga populasi dalam penelitian ini berjumlah 300 jenis obat. Sampel dalam penelitian ini adalah jenis obat yang tergolong ke dalam kelompok A (pemakaian terbanyak) berdasarkan analisis ABC yang terdiri dari 5 jenis obat yaitu obat Paracetamol, Folamil Genio, Lansoprazole, Amlodipine dan Domperidone. Jenis data dalam penelitian ini adalah data kuantitatif. Sumber data dalam penelitian ini adalah data sekunder. Data sekunder adalah data yang diperoleh atau diambil dari sumber-sumber yang telah ada sebelumnya. Dalam penelitian ini data sekunder yaitu jumlah permintaan obat dari bulan Januari 2020 hingga September 2021, data penjualan, biaya pesan dan biaya simpan pada Apotek Lestari. Dalam penelitian ini metode yang digunakan untuk pengumpulan data antara lain studi literature dan dokumentasi Langkah-langkah yang dilakukan dalam menganalisis data, yaitu memilih sampel obat dengan cara mengelompokkan obat kedalam metode ABC sehingga obat golongan A yaitu obat pemakaian terbanyak yang akan diteliti. Meramalkan jumlah permintaan obat golongan A dengan metode 
peramalan. Menghitung jumlah persediaan dengan metode EOQ dengan tujuan untuk meminimalkan total biaya persediaan dan pemesanan obat.

\section{Hasil dan Pembahasan}

Data yang digunakan dalam penelitian ini adalah data penjualan obat pada Apotek Lestari periode Januari 2020 sampai September 2021. Berdasarkan data tersebut diperoleh obat yang terjual sebanyak 300 jenis obat dan akan dilakukan pengelompokan obat menggunakan metode $\mathrm{ABC}$ untuk mendapatkan sampel yang akan diteliti. Berikut adalah hasil analisis ABC pada Apotek Lestari periode Januari 2020 sampai September 2021.

Tabel 1. Pengelompokan Obat Berdasarkan Metode ABC

\begin{tabular}{|c|rr|r|r|r|}
\hline Kelompok & \multicolumn{2}{|c|}{ Nilai Investasi } & \% Nilai Investasi & Item Obat & \% Item Obat \\
\hline $\mathrm{A}$ & $\mathrm{Rp}$ & 2.232 .527 .000 & $70 \%$ & 5 & $2 \%$ \\
\hline $\mathrm{B}$ & $\mathrm{Rp}$ & 667.575 .000 & $21 \%$ & 82 & $27 \%$ \\
\hline $\mathrm{C}$ & $\mathrm{Rp}$ & 303.101 .000 & $9 \%$ & 213 & $71 \%$ \\
\hline Total & $\mathrm{Rp}$ & 3.203 .203 .000 & $100 \%$ & 300 & $100 \%$ \\
\hline
\end{tabular}

Sumber: Pengolahan Data, 2021

Pada penelitian ini peneliti memfokuskan pada obat kelompok A yang terdiri dari Paracetamol $500 \mathrm{mg}$, Folamil Genio, Lansoprazole, Amlodipine $5 \mathrm{mg}$ dan Domperidone, yang diperoleh berdasarkan perhitungan $\mathrm{ABC}$ untuk dilakukan perhitungan lanjutan dengan menggunakan metode EOQ dan ROP yaitu untuk menentukan jumlah pemesanan ekonomis dan waktu pemesanan kembali. Pengendalian persediaan obat kelompok A harus diperhatikan agar terhindar dari kekosongan stok mengigat kegunaanya sangat dibutuhkan.

Setelah melakukan pengelompokan obat selanjutnya sampel yang terpilih akan di lakukan peramlan sebelum memasuki metode EOQ. Adapun peramalan 5 jenis obat dapat dilihat pada Tabel 2.

Tabel 2. Peramalan 5 Jenis Obat

\begin{tabular}{|l|l|r|}
\hline \multicolumn{1}{|c|}{ Nama Obat } & \multicolumn{1}{c|}{ Jenis Peramalan Terpilih } & Hasil Peramalan \\
\hline Paracetamol & exponential smoothing dengan $\alpha=0,2$ & 556 Tablet \\
\hline Folamil Genio & exponential smoothing dengan $\alpha=0,4$ & 668 Botol \\
\hline Lansoprazole & exponential smoothing dengan $\alpha=0,5$ & 477 Tablet \\
\hline Amlodipine & exponential smoothing dengan $\alpha=0,1$ & 465 Tablet \\
\hline Domperidone & exponential smoothing dengan $\alpha=0,3$ & 349 Tablet \\
\hline
\end{tabular}

Sumber: Pengolahan Data, 2021

Berikut adalah data biaya biaya pesan dan biaya simpan di Apotek Lestari:

a. Biaya Pemesanan (A).

Berdasarkan wawancara, rata-rata waktu dibutuhkan dalam tiap kali melakukan pemesanan adalah 10 menit. Tarif telepon lokal adalah Rp 250 per 2 menit (PT Telkom Indonesia, 2021), biaya untuk 10 menit telepon adalah $\mathrm{Rp}$ 1.250. Dalam sebulan Apotek Lestari menggunakan telepon hanya 1 kali, apabila dalam setahun maka total biaya telepon Rp 1.250 x $12=\operatorname{Rp} 15.000$. 
Berdasar hasil wawancara dengan informan, alat tulis kantor (ATK) yang digunakan untuk memesan obat adalah buku tukar faktur seharga Rp 7.000 dan sekotak pulpen seharga Rp 18.000. ATK tersebut digunakan selama setahun pemakaian. Maka total biaya ATK adalah Rp 25.000.

Total biaya pesan = Biaya telepon + Biaya alat tulis kantor

b. Biaya Simpan (I).

$$
\begin{aligned}
& =\operatorname{Rp} 15.000+\operatorname{Rp} 25.000 \\
& =\operatorname{Rp} 40.000
\end{aligned}
$$

Biaya simpan Apotek Lestari terdiri dari biaya listrik dan gaji karyawan. Biaya listrik adalah Rp 1.445/kWh (PT PLN Indonesia, 2021). Di gudang penyimpanan terdapat 4 buah bohlam dengan besar daya sebuah bohlam 25 watt. Maka total daya listrik 4 buah bohlam adalah 100 Watt atau jika diubah ke $\mathrm{kWh}$ menjadi $0,1 \mathrm{kWh}$. Waktu pakai adalah 16 jam/hari (dari jam 4 sore hingga 7 pagi) atau 5.840 jam/365 hari (dalam setahun). Maka total biaya listrik Apotek Lestari dalam setahun adalah:

Biaya Listrik = Daya Listrik $\mathrm{x}$ Waktu Pakai $\mathrm{x}$ Harga per $\mathrm{kWh}$

$$
\begin{aligned}
& =0,1 \mathrm{kWh} \times 5.840 \mathrm{jam} \times \mathrm{Rp} 1.445 / \mathrm{kWh} \\
& =\operatorname{Rp} 843.880
\end{aligned}
$$

Gaji karyawan yang bertugas dalam menjaga kebersihan gudang dan pengontrolan area gudang pada Apotek Lestari adalah dalam sebulan Rp 1.000.000. Maka total gaji karyawan dalam setahun adalah Rp 12.000.000.

Total biaya simpan Apotek Lestari adalah = Biaya Listrik + Gaji Karyawan

$$
\begin{aligned}
& =\operatorname{Rp} 843.880+\operatorname{Rp} 12.000 .000 \\
& =\operatorname{Rp} 12.843 .880
\end{aligned}
$$

Selanjutnya hasil perhitungan EOQ untuk kelima sampel obat dapat dilihat pada Tabel 3.

Tabel 3. Hasil Perhitungan EOQ untuk Kelima Jenis Sampel Obat

\begin{tabular}{|l|r|r|r|r|}
\hline \multicolumn{1}{|c|}{ Nama Obat } & \multicolumn{1}{c|}{ EOQ } & \multicolumn{1}{c|}{ SS } & \multicolumn{1}{c|}{ ROP } & \multicolumn{1}{c|}{ Maksimum stok } \\
\hline Paracetamol & 152 & 54 & 147 & 218 \\
\hline Folamil Genio & 183 & 45 & 176 & 243 \\
\hline Lansoprazole & 130 & 50 & 128 & 191 \\
\hline Amlodipine & 127 & 39 & 120 & 177 \\
\hline Domperidone & 95 & 40 & 88 & 142 \\
\hline
\end{tabular}

Sumber: Pengolahan Data, 2021

\section{Kesimpulan}

Berdasarkan hasil pengolahan data dan analisis yang telah dilakukan, maka dapat disimpulkan bahwa nilai peramalan permintaan obat bulan Oktober 2021 yang terpilih yaitu dengan metode exponential smoothing untuk obat Paracetamol adalah 556 tablet, obat Folamil Genio adalah 668 botol, obat Lansoprazole adalah 477 tablet, obat Amlodipine adalah 465 tablet dan obat Domperidone adalah 349 tablet. Jumlah pemesanan yang ekonomis (EOQ) untuk obat Paracetamol adalah 152 tablet dengan total cost $\mathrm{Rp} 292.601$, untuk obat Folamil Genio adalah 183 botol dengan total cost Rp 292.579, untuk obat Lansoprazole adalah 130 tablet dengan total cost Rp 292.616, untuk obat Amlodipine adalah 127 tablet dengan total cost Rp 292.619 dan untuk obat Domperidone adalah 95 tablet dengan total cost $\mathrm{Rp} 292.615$. 


\section{Daftar Pustaka}

Arsana, P. J., 2016, Manajemen Pengadaan Barang dan Jasa, Yogyakarta: CV Budi Utama.

Darmawa, N. P, Peranginangin, J. P, dan Herowat, R, 2021, Analisis Pengendalian Persediaan Obat BPJS Kategori A(Always) dan E(Esensial) dengan Menggunakan Metode ABC, VEN Dan EOQ di IFRS Bhayangkara Tingkat III Nganjuk, Journal of Pharmaceutical Science and Clinical Research, Vol 01, Halaman: 20-32.

Dyatmika, S. B dan Krisnadewara, P. D, 2017, Pengendalian Persediaan Obat Generik dengan Metode Analisis ABC, Metode Economic Order Quantity (EOQ), dan Reorder Point (ROP) Di Apotek XYZ Tahun 2017, Jurnal MODUS, ISSN 0852-1875, Vol 30, No 1, Halaman: 71-95.

Fikram, M. N., 2019, Optimasi Persediaan Bahan Baku dengan Analisis ABC dan Periodic Review PT XYZ, Jurnal Optimasi Teknik Industri, Vol. 1, No. 2, Hal. 21-25.

Fitra., Khairani, M., dan Indrawan, S., 2020, Perencanaan Persediaan Bahan Bakar Minyak PT X, JURNAL UNITEK, 12(1), 1-9.

Habibi, R., dan Suryansah, A., 2020, Aplikasi Prediksi Jumlah Kebutuhan Perusahaan, Bandung: Kreatif Industri Nusantara.

Loloa, W. A, Widodoa, W. I, dan Mpilaa, D. A, 2020, Analisis Perencanaan dan Pengadaan Obat Antibiotik Berdasarkan Metode ABC Indeks Kritis di Instalasi Farmasi Rumah Sakit Advent Manado, JURNAL MIPA, Vol 10, No 1, Halaman: $10-14$.

Martono, R. V., 2018, Manajemen Logistik, Jakarta: PT Gramedia Pustaka Utama.

Mesra, T., Melliana, dan Sitorus, A.A., (2021), Perencanaan Persedian Argon Di Cv Cahaya Teknik Abadi Jurnal ARTI (Aplikasi Rancangan Teknik Industri), VOL.16 NO 1 (2021) Desember 2020 - Mei 2021, Hal: 72-78

Mesra, T., Fitra, dan Anggraini, R., Pengendalian Persediaan Bahan Pendukung Pemurnian Minyak Sawit di PT XYZ, Buletin Utama Teknik, Volume 15 No. 1, Bulan September.

Sondakh, F. F., Astuty, W dan Uneputty, J, 2018, Analisis Perencanaan Dan Pengadaan Obat Antibiotik Berdasarkan ABC Indeks Kritis di Instalasi Farmasi RSU Monompia Kotamobagu, Jurnal Ilmiah Farmasi-UNSRAT, ISSN 2302-2493, Vol 7, No 4, Halaman: 42-50.

Susanto, M. V, dan Permanasari V. Y, 2019, Penerapan Metode ABC Indeks Kritis dalam Pengelolaan Persediaan Obat di Instalasi Farmasi Rumah Sakit XYZ Pekanbaru, Riau, Jurnal ARSI, Volume 5, Nomor 2, Halaman: 72-84. 